\title{
Circulating tumor cells: the substrate of personalized medicine?
}

\author{
Bryan T. Greene ${ }^{1,2}{ }^{+}$, Andrew D. Hughes ${ }^{3 \dagger}$ and Michael R. King ${ }^{3}$ \\ 'BioCytics, Inc., Huntersville, NC, USA \\ ${ }^{2}$ Carolina BioOncology Institute, PLLC, Huntersville, NC, USA \\ ${ }^{3}$ Department of Biomedical Engineering, Cornell University, Ithaca, NY, USA
}

Edited by:

Michael R. King, Cornell University, USA

\section{Reviewed by:}

Justin Lathia, Lerner Research

Institute, USA

Kuldeepsinh Prabhudattsinh Rana,

Consulting, India

Sujata Kumari Bhatia, Harvard

University, USA

\section{*Correspondence:}

Bryan T. Greene, BioCytics, Inc., 9801

W. Kincey Avenue, Suite 145,

Huntersville, NC 28078, USA.

e-mail: bryan.greene@biocytics.com

${ }^{\dagger}$ Bryan T. Greene and Andrew

$D$. Hughes have contributed equally

to this work.
Circulating tumor cells (CTCs) are believed to be responsible for the development of metastatic disease. Over the last several years there has been a great interest in understanding the biology of CTCs to understand metastasis, as well as for the development of companion diagnostics to predict patient response to anti-cancer targeted therapies. Understanding CTC biology requires innovative technologies for the isolation of these rare cells. Here we review several methods for the detection, capture, and analysis of CTCs and also provide insight on improvements for CTC capture amenable to cellular therapy applications.

Keywords: circulating tumor cells, leukapheresis, leukopak, selectins, EpCAM

\section{INTRODUCTION}

At its basic definition, cancer is the uncontrolled growth of cells in the body. Over the past several decades, our understanding of cancer has greatly improved and it is now clear that while the basic definition of cancer holds true, cancer is an extremely complex disease composed of various molecular alterations and phenotypic changes. The vast majority of cancer deaths occur due to metastasis of the primary tumor to distant sites via circulating tumor cells (CTCs) in the circulation. CTCs are extremely rare. Over the past $5-10$ years, various methodologies and platforms have been developed to isolate CTCs for further characterization and molecular analyses. The emergence of these technologies have spurred a great interest in CTCs and researchers and clinicians are realizing the importance of CTCs in cancer biology as well as their use in cancer diagnosis and therapy.

While the potential of using CTCs to guide patient treatment remains promising, the rate-limiting step for widespread use of CTCs in the clinic remains the lack of robust and high-throughput technologies for isolation of these rare cells. In fact, in most cases, most CTC isolation platforms isolate a few to several hundred CTCs, rendering the functional characterization of these cells extremely difficult (Maheswaran and Haber, 2010). This review is not intended to be an exhaustive description of all CTC isolation technologies (for further reading, see Hughes and King, 2012), but instead will provide a historical framework for CTC isolation and then focus on current "state of the art" for isolation of viable CTCs and their potential use in cell therapy.

\section{CTC ISOLATION: FINDING A NEEDLE IN A HAYSTACK CTCS IN THE CLINIC: HISTORICAL PERSPECTIVE}

Great interest in the CTC field was ignited by the introduction of the CellSearch system (Allard et al., 2004). The CellSearch system (Veridex, Raritan, NJ, USA) was FDA cleared in January 2004 as a prognostic tool for identifying and counting CTCs in a blood sample to predict progression-free and overall survival in patients with metastatic breast cancer. In 2007 and 2008, the CellSearch system was cleared as an aid for monitoring metastatic colorectal and prostate cancer patients, respectively. The CellSearch system, like many other platforms, relies on the expressed surface ligand epithelial cellular adhesion molecule (EpCAM) and immunomagnetic capture to isolate CTCs. CTCs are subsequently stained and quantified using an antibody against cytokeratins. Contaminating leukocytes are identified using an antibody against CD45. CTCs are defined as cytokeratin positive and CD45 negative.

The CellSearch system made possible, for the first time, the capture of CTCs in a standardized and highly reproducible fashion within a clinical context. Our group was one of the first to offer the CellSearch test and to date we have performed approximately 1,500 CellSearch CTC tests on blood from over 150 metastatic cancer patients. Our data from this aggregate of patients (unpublished) is consistent with an earlier study showing that a significant fraction of blood samples tested using the CellSearch system lacked CTCs (Allard et al., 2004). In addition, CTC outputs from the CellSearch system typically have low yield and purity (Allard et al., 2004). 


\section{NEXT GENERATION CTC CAPTURE PLATFORMS}

Since the introduction of the CellSearch system, several groups have invested significant time and resources in developing newer CTC isolation technologies that overcome the barriers to widespread clinical use associated with the CellSearch system, namely low yield, low purity, and low throughput. These include methodologies that isolate CTCs based on size or other physical properties (Muller et al., 2005; Wulfing et al., 2006; Mohamed et al., 2009; Tan et al., 2009). For example, the MagSweeper uses a slowly rotating magnetic stir bar coated with antibodies against EpCAM to capture CTCs from unfractionated blood samples, thus improving throughput due to the elimination of sample preparation steps (Talasaz et al., 2009). Recent work has used the MagSweeper to enrich CTCs from patient samples, which were then individually evaluated for expression levels of 87 genes using a microfluidicbased qRT-PCR technique. A high degree of expression heterogeneity was observed between CTCs, with generally high expression levels of epithelial-to-mesenchymal transition (EMT)-related genes such as TGF $\beta 1$, vimentin, and CXCR4 (Powell et al., 2012). Additionally, comparison of four breast cancer cell lines and the isolated primary CTCs showed particularly disparate expression profiles, suggesting that cancer cell lines are of dubious utility as a model for CTC research.

The CTC-chip and herringbone (HB)-chip use antibodycoated microfluidic devices for capture of EpCAM ${ }^{+}$CTCs from unprocessed whole blood (Nagrath et al., 2007; Maheswaran et al., 2008; Stott et al., 2010a). The HB-chip is more amenable to manufacturing for high-throughput applications and CTCs captured on the device are of sufficiently high purity and yield to be interrogated for molecular alterations (Stott et al., 2010b). A recent observation has been the capture of clusters of CTCs, called circulating tumor microemboli (CTM), from several prostate and lung cancer patients using the HB-chip (Stott et al., 2010a). Capture of CTM has also been observed using a slide-based high definition CTC (HD-CTC) imaging platform (Cho et al., 2012). Indeed, in a recent study using the "HD-CTC assay" on samples from 68 patients with metastatic breast, prostate, or pancreatic cancer, clusters of two or more CTCs were identified in $88 \%$ of patients (Marrinucci et al., 2012). Interestingly, we have made similar observations from samples processed on the CellSearch system (Figure 1). It is unclear what the clinical significance of these CTC clusters is, although a notable hypothesis suggests that these clusters may serve as a potential mechanism to prevent anoikis thereby enhancing metastatic potential (Zhang et al., 2008).

The HD-CTC technique is notable in that CTCs in a sample of blood are enriched only by erythrocyte lysis, and then automated scanning is used to identify CTCs based on fluorescent probes. This is important because the only underlying assumption is that CTCs will not lyse along with erythrocytes in ammonium chloride solution, which is reasonable. Many other CTC isolation techniques rely on specific surface markers, such as EpCAM for positive selection or CD45 for negative selection. It has been shown that EpCAM, while widely expressed across cancer types, is not universally expressed (Went et al., 2004). Thus CTC capture based on surface marker expression induces a bias of unknown consequence. Currently, the HD-CTC technique identifies CTCs based on cytokeratin expression and CD45 absence, which imposes

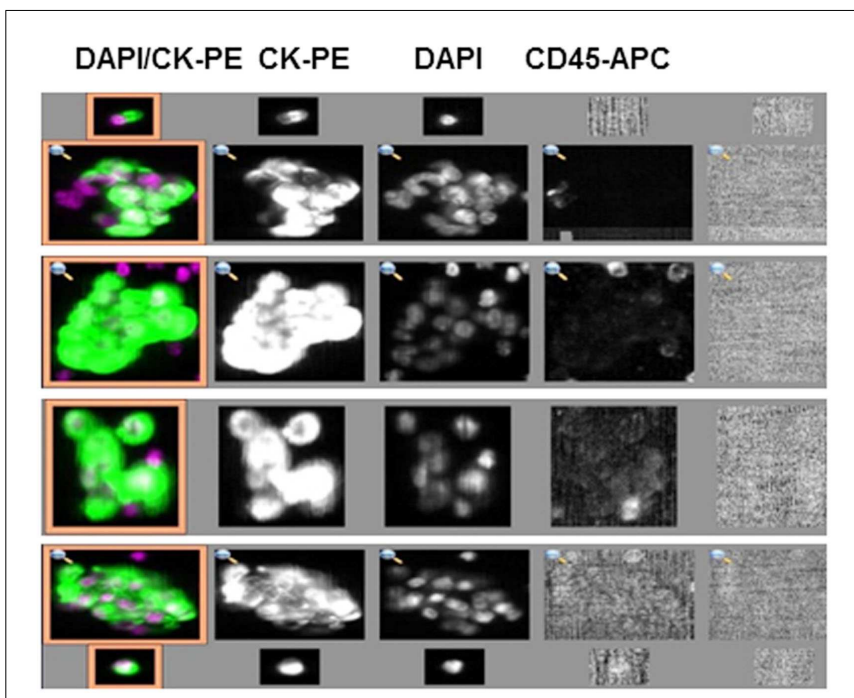

FIGURE 1 | Circulating tumor cell clusters captured from a breast cancer patient using the CellSearch system. (CK, cytokeratin; PE, phycoerythrin; APC, allophycocyanin; DAPI, 4',6-diamidino-2-phenylindole).

another bias in that cancer cells that undergo EMT may not produce cytokeratin (Marrinucci et al., 2012). However, the platform is amenable to the use of alternate probes that are more universal. A significant challenge remains for identifying a universal biomarker for CTCs.

Alternate approaches to CTC isolation are currently in development, based on the generally held observation that CTCs are larger than leukocytes, by processing cell samples through a filter. A commercially available version, Isolation by Size of Epithelial/Trophoblastic Tumor cells, or ISET (RareCell Diagnostics), works by simultaneously lysing erythrocytes and fixing remaining cells in paraformaldehyde, and then perfusing the sample through a polycarbonate filter with $8 \mu \mathrm{m}$ pores. CTCs thus remain on the filter, which can be stored prior to analysis of captured CTCs. Capture sensitivity has been reported to be one CTC per milliliter of blood (Vona et al., 2000). CTCs have been analyzed by in situ immunohistochemistry as well as real-time RT-PCR (Pinzani et al., 2006; Krebs et al., 2012). Interestingly, a recent study found CTM in $43 \%$ of patients studied, and evaluation by Ki67 immunohistochemistry showed that captured CTC were proliferative while CTM were not (Krebs et al., 2012).

An alternative form of filtration device uses a parylene membrane that allows for formation of pores of controlled size and shape. In a proof of concept study, a device was constructed to process whole blood and $\sim 90 \%$ recovery was achieved with spiked samples (Zheng et al., 2007). A promising aspect of this device is that the filtration was performed within minutes, showing a higher throughput than most microfluidic methods. An integrated electrode system allows for in situ electrolysis of captured cells to facilitate rapid harvesting of genetic material. More recently, this parylene filter system has been used to capture CTCs from patient samples (Lin et al., 2010).

Our group has developed a technique for capturing CTCs based on their ability to adhere to endothelium during extravasation 
(Hughes et al., 2012a,b). This technique relies on the binding of CTCs to microtubes coated with a combination of E-selectin protein and epithelial specific antibodies absorbed to an immobilized nanotube layer and perfused under flow. Selectin-mediated capture mimics the normal and malignant process of cell adhesion to blood vessels during metastasis and suggests that CTCs captured using this approach may be more invasive and have undergone EMT to some degree. The CTCs captured by this approach remain viable and can be cultured short term to potentiate subsequent analysis. A halloysite nanotube coating enables $>50 \%$ purity. It is interesting to note that in general more CTCs were isolated and identified using the selectin-based technique compared to CellSearch on ostensibly identical samples (i.e., two tubes were drawn from each patient and processed by either technique in parallel; Figure 2). Indeed, 7 of 12 patient samples were positive for CTCs using CellSearch, while 12 of 12 were positive using our device. Other techniques have similarly found significant discord when using CellSearch on parallel samples; generally more CTCs are found, suggesting that CellSearch neglects to identify many CTCs and has a tendency to report false negatives (Lin et al., 2010; Kirby et al., 2012; Krebs et al., 2012; Marrinucci et al., 2012).

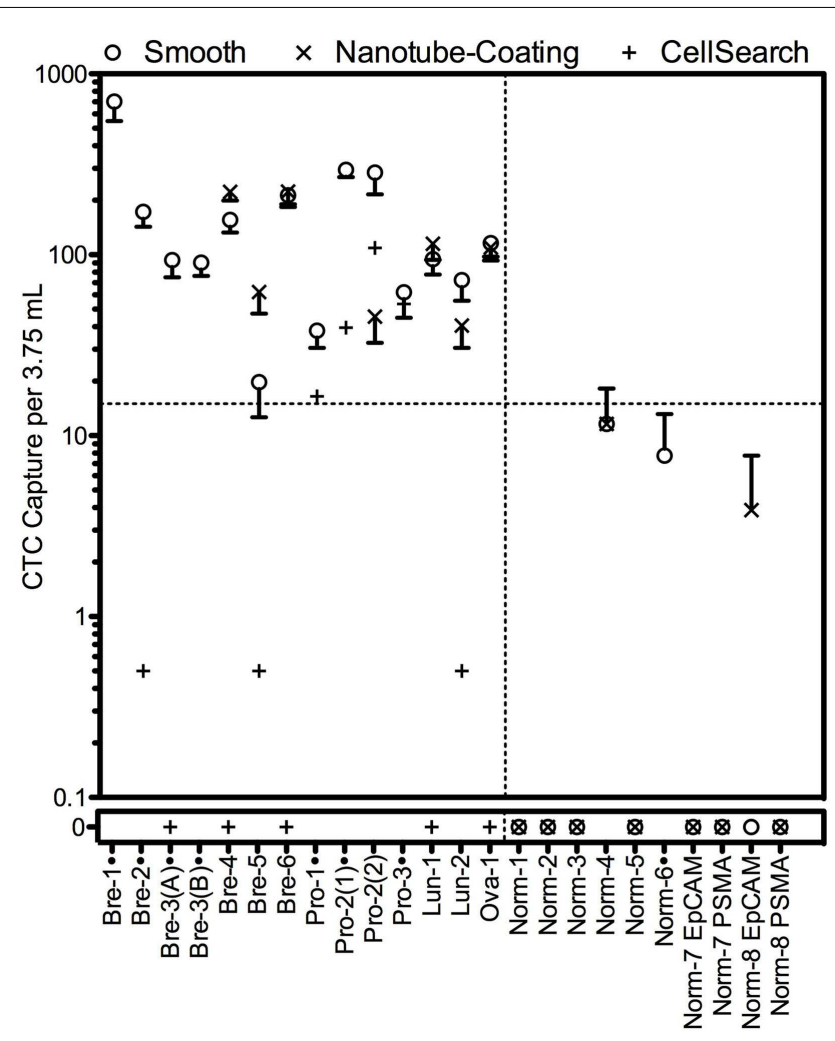

FIGURE 2 | Circulating tumor cell capture using the selectin-functionalized microtube device compared to CTC capture of identical samples using CellSearch. The microtube device was prepared with or without a halloysite nanotube coating. Figure from Hughes and King (2012).

\section{THERAPEUTIC APPLICATIONS OF CTCS}

The molecular characterization of CTCs may provide opportunities for therapeutic targeting of CTCs or real-time monitoring of targeted anti-cancer agents (Leversha et al., 2009; Punnoose et al., 2010). Maheswaran et al. (2008) identified mutations in epidermal growth factor receptor (EGFR) in CTCs from lung cancer patients and showed that after continued anti-EGFR therapy, a resistance-associated EGFR mutation emerged. In a separate study using multicolor flow cytometry to rapidly detect and analyze CTCs following erythrocyte lysis, researchers monitored the expression of EGFR in its phosphorylated and unphosphorylated states during the time in which patients were being treated with different therapies for squamous cell carcinoma of the head and neck (SCCHN). The researchers found interesting correlations between different treatment combinations, CTC counts, and EGFR activation (Tinhofer et al., 2012).

Using multiple CTC isolation platforms, several groups have examined Her-2 expression on CTCs and shown in some cases discordance of Her-2 expression between the primary tumor and CTCs (Hayes et al., 2002; Meng et al., 2004; Punnoose et al., 2010; Riethdorf et al., 2010). It follows that if CTCs do not express the same markers as the primary tumor cells, then drugs chosen based on primary tumor markers will be ineffective against CTCs and the secondary tumors they seed. Comprehensive molecular profiling of CTCs in the clinic remains hampered by the low yield and low throughput of most CTC platforms.

The idea of harvesting CTCs from a patient and then studying these CTCs to rapidly determine the best possible treatment for that patient is compelling. The feasibility of such a scheme has been demonstrated to some degree using the geometrically enhanced differential immunocapture (GEDI) device, which is akin to the CTC-chip developed by Toner and colleagues (Nagrath et al., 2007) with altered micropost arrangements to promote collisions with CTCs based on size (Gleghorn et al., 2010). In the most recent study using this device, CTCs were captured within the chip and then treated with different chemotherapeutics in situ to assay drug susceptibility (Kirby et al., 2012).

Cellular therapy has recently emerged as a promising approach for treatment of malignancy. Tumor infiltrating lymphocytes or gene-engineered $\mathrm{T}$ cells have been used with some success in metastatic cancer patients (Restifo et al., 2012). Provenge is the first active cellular therapy approved by the Food and Drug administration for the treatment of prostate cancer (Wesley et al., 2012). Provenge is manufactured by culturing a patient's peripheral blood mononuclear cells (PBMNCs) and antigen presenting cells with the tumor-associated antigen prostatic acid phosphatase and granulocyte-macrophage colony stimulating factor. Treatment consists of three infusions at approximately 2 -week intervals. Provenge is the first autologous anti-cancer cell therapy shown to provide a survival advantage (Wesley et al., 2012).

One intriguing possibility is the ex vivo manipulation of CTCs for cellular therapy of cancer. The rate-limiting step in this approach is the low yield associated with many CTC platforms. In theory, if enough CTCs could be obtained and expanded, they could be used as a platform for the development of personalized tumor immunotherapy. An alternative approach for increasing 
the amount of CTCs collected from patients is through leukapheresis (Figure 3). Leukapheresis is a laboratory procedure in which white blood cells (WBCs or PBMNCs) or peripheral blood stem cells (PBSCs) are separated from blood. During leukapheresis, a patient's blood is passed through a machine that removes the WBCs or PBSCs and then returns the balance of blood back to the patient. This process usually takes 3 or $4 \mathrm{~h}$ to filter the entire blood supply (approximately 4-61). Collected PBSCs may be used in autologous PBSC transplants to "rescue" the immune system and blood-forming cells of cancer patients following high-dose chemotherapy (Montgomery and Cottler-Fox, 2007). Leukapheresis is common in the stem cell transplant setting for treatment of lymphomas, multiple myeloma, and some solid tumors. The cell therapy Provenge uses leukapheresis to obtain PBMNCs and antigen presenting cells for further manipulation (Wesley et al., 2012).

The product of leukapheresis, termed a leukopak, may also contain CTCs. In theory, one may be able to increase the CTC yield by filtering the entire blood supply, thereby capturing every CTC in the body as opposed to the $0.1-0.2 \%$ that would be present in a 7.5-ml blood sample. An increase in CTC yield would improve the diagnostic utility of CTCs and potentially facilitate in vitro drug screens on CTCs to predict patient response. Our own group has a Western IRB approved protocol and informed consent for performing leukapheresis on cancer patients in a private, community based, Phase I oncology clinic. In a recent proof of concept study, Eifler et al. (2011) showed using spike-in experiments that isolation of CTCs via leukapheresis followed by elutriation to separate cells based on size, is feasible. Using fluorescence activated cell sorting (FACS) the authors showed high recovery of CaOV-3 cells spiked into leukopaks obtained from healthy volunteers (Eifler et al., 2011). Importantly, no tumor cell events were observed from leukopaks that had not been spiked with tumor cells. Interestingly, analysis by flow cytometry also revealed a CD45 ${ }^{+}$and EpCAM $^{+}$dual positive population of cells that occurred at the highest frequency in the leukopak, and decreased with increasing elutriation fraction. B-lymphocytes were associated with EpCAM binding suggesting that leukocyte lineage specific markers should be used in negative depletion strategies prior to CTC capture, rather than CD45 which could bias results (Eifler et al., 2011).

Following elutriation, CTCs were further captured using FACS or EpCAM-coupled magnetic beads (Eifler et al., 2011).
Immunomagnetic bead adsorption recovered $10 \%$ of tumor cells with a median purity of 3.5\% (Eifler et al., 2011). EpCAM-coupled magnetic bead isolation of CTCs from leukopaks is not ideal, in part because of the cost associated with using such a large amount of EpCAM antibody.

More recently, several groups are further exploring the potential of leukapheresis/apheresis for use in CTC isolation. Stratmann et al. (2012) obtained blood samples and buffy coat by apheresis from breast and pancreatic patients (non-metastatic and metastatic). These samples were then processed using several CTC technologies. Importantly, all methods were able to detect CTCs in buffy coat from both non-metastatic and metastatic cancer patients and newer CTC isolation platforms (i.e., filer based, etc.) showed in general a better yield of CTCs in comparison to CellSearch. In an additional study, Stoecklein et al. (2012) showed in breast cancer patients that higher CTC detection frequencies and numbers could be obtained using leukapheresis products as compared to matched peripheral blood samples from the same patient. Moreover, captured CTCs were amendable to comparative genomic hybridization (Stoecklein et al., 2012). Taken together, these results show the exciting opportunity and potential of using leukapheresis for CTC isolation. Clearly, newer technologies that can accommodate large blood volumes are needed for CTC isolation following leukapheresis to be used widespread in the clinic. In future studies, our group is planning to investigate the feasibility of processing large volumes using the selectin-based approach.

One of the more ambitious approaches to the incorporation of CTCs in the design of new cancer therapies is to consider CTCs as a target for therapy. This is promising considering that $90 \%$ of cancer deaths are caused by metastasis (Wittekind and Neid, 2005). The disruption of cancer cell dissemination would thus represent a powerful therapeutic strategy. Photoacoustic flow cytometry has been developed in recent years that allows for the detection and ablation of CTCs in vivo. This technology functions by shining a laser through the skin into a vessel that is up to $3 \mathrm{~mm}$ deep and detecting the acoustic vibrations that result from the absorption of laser light by target nanoparticles (Zharov et al., 2007). The most direct application of this technology is for the detection of circulating melanoma cells, capitalizing on their endogenous expression of melanin nanoparticles for detection (Nedosekin et al., 2011). Increasing the incident laser energy can lead to the generation of heat by the vibrating nanoparticles to a sufficient degree that

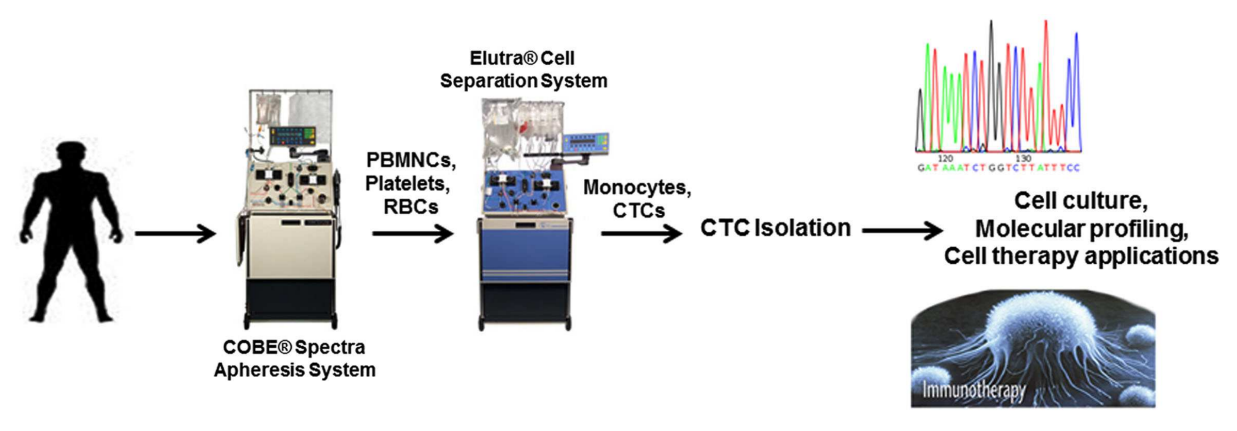

FIGURE 3 | Illustration showing potential applications of CTCs following isolation after leukapheresis. 
the flowing melanin-containing cells are ablated (Galanzha et al., 2009b). This technology can be applied to less photo-distinct CTCs using targeted gold nanoparticles, for example to target CD44 to detect and eradicate cancer stem cells (Galanzha et al., 2009a).

Our group has proposed the idea of a shunt device that can be implanted into the vasculature to capture and eradicate CTCs in vivo. This device is composed of a selectin-functionalized microtube that will induce the rolling of CTCs along the luminal surface. In one realization of this device, the microtube lumen is co-functionalized with tumor necrosis factor-related apoptosisinducing ligand (TRAIL, also known as Apo2) that signals cell death to cancer cells via the caspase pathway. A validation study in vitro achieved a $30 \%$ kill rate of cancer cells without compromising leukocyte viability (Rana et al., 2009). Ongoing studies are evaluating the benefits of manipulating the nanoscale topography of the luminal surface to achieve greater CTC eradication. An alternate version of this device is a microtube shunt that is functionalized with a halloysite nanotube coating which is then coated with targeted liposomes. Liposomes containing the anti-cancer drug doxorubicin are coated with polyethylene glycol (PEG) and E-selectin. Thus flowing cancer cells roll on the selectin-coated liposomes, and we have shown that these liposomes remain on the cell surface and are internalized (Mitchell et al., 2012).

\section{REFERENCES}

Allard, W. J., Matera, J., Miller, M. C., Repollet, M., Connelly, M. C., Rao, C., Tibbe, A. G., Uhr, J. W., and Terstappen, L. W. (2004). Tumor cells circulate in the peripheral blood of all major carcinomas but not in healthy subjects or patients with nonmalignant diseases. Clin. Cancer Res. 10, 6897-6904.

Cho, E. H., Wendel, M., Luttgen, M., Yoshioka, C., Marrinucci, D., Lazar, D., Schram, E., Nieva, J., Bazhenova, L., Morgan, A., Ko, A. H., Korn, W. M., Kolatkar, A., Bethel, K., and Kuhn, P. (2012). Characterization of circulating tumor cell aggregates identified in patients with epithelial tumors. Phys. Biol. 9, 016001.

Eifler, R. L., Lind, J., Falkenhagen, D., Weber, V., Fischer, M. B., and Zeillinger, R. (2011). Enrichment of circulating tumor cells from a large blood volume using leukapheresis and elutriation: proof of concept. Cytometry B Clin. Cytom. 80, 100-111.

Galanzha, E. I., Kim, J. W., and Zharov, V. P. (2009a). Nanotechnology-based molecular photoacoustic and photothermal flow cytometry platform for in-vivo detection and killing of circulating cancer stem cells. J. Biophotonics 2, 725-735.

Galanzha, E. I., Shashkov, E. V., Spring, P. M., Suen, J. Y., and Zharov, V. P. (2009b). In vivo, noninvasive, labelfree detection and eradication of circulating metastatic melanoma cells

\section{CONCLUSION}

The true potential of CTCs has yet to be realized because of limits in technology used to capture these cells and our lack of a complete understanding of metastasis. This is complicated by the fact that our understanding of CTCs is subject to the techniques available to identify and isolate CTCs, and the biases inherent to them. Nevertheless, progress has been made to advance the state of knowledge and probe the use of CTCs in more active roles than simply enumeration. CTCs have the potential to serve as a readily accessible, transparent window into an individual's disease. The ideal device is one that can be used at the point of care to quickly harvest CTCs and make them available for subsequent analyses. One may envision how such a scheme would produce personalized cancer therapies by allowing clinicians to evaluate susceptibilities in the laboratory, and create tailored therapies for each individual. There are myriad possibilities if CTCs can be isolated at high-throughput and purity without bias.

\section{ACKNOWLEDGMENTS}

This work was funded by National Institutes of Health, Grant No. CA143876 (Michael R. King), by a National Science Foundation Graduate Research Fellowship (Andrew D. Hughes), and by BioCytics, Inc. (Bryan T. Greene).

Vos, C., Gleghorn, J. P., Santana, S. M., Liu, H., Smith, J. P., Navarro, V. N., Tagawa, S. T., Bander, N. H., Nanus, D. M., and Giannakakou, P. (2012). Functional characterization of circulating tumor cells with a prostate-cancer-specific microfluidic device. PLoS ONE 7, e35976. doi: 10.1371/journal.pone.0035976

Krebs, M. G., Hou, J. M., Sloane, R., Lancashire, L., Priest, L., Nonaka, D., Ward, T. H., Backen, A., Clack, G., Hughes, A., Ranson, M., Blackhall, F. H., and Dive, C. (2012). Analysis of circulating tumor cells in patients with non-small cell lung cancer using epithelial markerdependent and -independent approaches. J. Thorac. Oncol. 7, 306-315.

Leversha, M. A., Han, J., Asgari, Z., Danila, D. C., Lin, O., GonzalezEspinoza, R., Anand, A., Lilja, H., Heller, G., Fleisher, M., and Scher, H. I. (2009). Fluorescence in situ hybridization analysis of circulating tumor cells in metastatic prostate cancer. Clin. Cancer Res. 15, 2091-2097.

Lin, H. K., Zheng, S. Y., Williams, A. J., Balic, M., Groshen, S., Scher, H. I., Fleisher, M., Stadler, W., Datar, R. H., Tai, Y. C., and Cote, R. J. (2010). Portable filter-based microdevice for detection and characterization of circulating tumor cells. Clin. Cancer Res. 16, 5011-5018.

Maheswaran, S., and Haber, D. A. (2010). Circulating tumor cells: a window into cancer biology and metastasis. Curr. Opin. Genet. Dev. 20, 96-99.

Maheswaran, S., Sequist, L. V., Nagrath, S., Ulkus, L., Brannigan, B., Collura, C. V., Inserra, E., Diederichs, S., Iafrate, A. J., Bell, D. W., Digumarthy, S., Muzikansky, A., Irimia, D., Settleman, J., Tompkins, R. G., Lynch, T. J., Toner, M., and Haber, D. A. (2008). Detection of mutations in EGFR in circulating lungcancer cells. N. Engl. J. Med. 359, 366-377.

Marrinucci, D., Bethel, K., Kolatkar, A., Luttgen, M. S., Malchiodi, M. Baehring, F., Voigt, K., Lazar, D., Nieva, J., Bazhenova, L., Ko, A. H., Korn, W. M., Schram, E., Coward, M., Yang, X., Metzner, T., Lamy, R., Honnatti, M., Yoshioka, C., Kunken, J., Petrova, Y., Sok, D., Nelson, D., and Kuhn, P. (2012). Fluid biopsy in patients with metastatic prostate, pancreatic and breast cancers. Phys. Biol. 9, 016003.

Meng, S., Tripathy, D., Shete, S., Ashfaq, R., Haley, B., Perkins, S., Beitsch, P., Khan, A., Euhus, D., Osborne, C., Frenkel, E., Hoover, S., Leitch, M., Clifford, E., Vitetta, E., Morrison, L., Herlyn, D., Terstappen, L. W., Fleming, T., Fehm, T., Tucker, T., Lane, N., Wang, J., and Uhr, J. (2004). HER-2 gene amplification can be acquired as breast cancer progresses. Proc. Natl. Acad. Sci. U.S.A. 101, 9393-9398. 
Mitchell, M. J., Chen, C. S., Ponmudi, V., Hughes, A. D., and King, M. R. (2012). E-selectin liposomal and nanotube-targeted delivery of doxorubicin to circulating tumor cells. J. Control Release 160, 609-617.

Mohamed, H., Murray, M., Turner, J. N., and Caggana, M. (2009). Isolation of tumor cells using size and deformation. J. Chromatogr. A 1216, 8289-8295.

Montgomery, M., and Cottler-Fox, M. (2007). Mobilization and collection of autologous hematopoietic progenitor/stem cells. Clin. Adv. Hematol. Oncol. 5, 127-136.

Muller, V., Stahmann, N., Riethdorf, S., Rau, T., Zabel, T., Goetz, A., Janicke, F., and Pantel, K. (2005). Circulating tumor cells in breast cancer: correlation to bone marrow micrometastases, heterogeneous response to systemic therapy and low proliferative activity. Clin. Cancer Res. 11, 3678-3685.

Nagrath, S., Sequist, L. V., Maheswaran, S., Bell, D. W., Irimia, D., Ulkus, L., Smith, M. R., Kwak, E. L., Digumarthy, S., Muzikansky, A., Ryan, P., Balis, U. J., Tompkins, R. G., Haber, D. A., and Toner, M. (2007). Isolation of rare circulating tumour cells in cancer patients by microchip technology. Nature 450, 1235-1239.

Nedosekin, D. A., Sarimollaoglu, M., Ye, J. H., Galanzha, E. I., and Zharov, V. P. (2011). In vivo ultra-fast photoacoustic flow cytometry of circulating human melanoma cells using near-infrared highpulse rate lasers. Cytometry 79A, 825-833.

Pinzani, P., Salvadori, B., Simi, L., Bianchi, S., Distante, V., Cataliotti, L., Pazzagli, M., and Orlando, C. (2006). Isolation by size of epithelial tumor cells in peripheral blood of patients with breast cancer: correlation with real-time reverse transcriptasepolymerase chain reaction results and feasibility of molecular analysis by laser microdissection. Hum. Pathol. 37, 711-718.

Powell, A. A., Talasaz, A. H., Zhang, H., Coram, M. A., Reddy, A., Deng, G., Telli, M. L., Advani, R. H., Carlson, R. W., Mollick, J. A., Sheth, S., Kurian, A. W., Ford, J. M., Stockdale, F. E., Quake, S. R., Pease, R. F., Mindrinos, M. N., Bhanot, G., Dairkee, S. H., Davis, R. W., and Jeffrey, S. S. (2012). Single cell profiling of circulating tumor cells: transcriptional heterogeneity and diversity from breast cancer cell lines. PLoS ONE 7, e33788. doi: 10.1371/journal.pone. 0033788

Punnoose, E. A., Atwal, S. K., Spoerke, J. M., Savage, H., Pandita, A., Yeh, R. F., Pirzkall, A., Fine, B. M., Amler, L. C., Chen, D. S., and Lackner, M. R. (2010). Molecular biomarker analyses using circulating tumor cells. PLoS ONE 5, e12517. doi: 10.1371/journal.pone.0012517

Rana, K., Liesveld, J. L., and King, M. R. (2009). Delivery of apoptotic signal to rolling cancer cells: a novel biomimetic technique using immobilized TRAIL and E-selectin. Biotechnol. Bioeng. 102, 1692-1702.

Restifo, N. P., Dudley, M. E., and Rosenberg, S. A. (2012). Adoptive immunotherapy for cancer: harnessing the $\mathrm{T}$ cell response. Nat. Rev. Immunol. 12, 269-281.

Riethdorf, S., Muller, V., Zhang, L., Rau, T., Loibl, S., Komor, M., Roller, M., Huober, J., Fehm, T., Schrader, I., Hilfrich, J., Holms, F., Tesch, H., Eidtmann, H., Untch, M., Von Minckwitz, G., and Pantel, K. (2010). Detection and HER2 expression of circulating tumor cells: prospective monitoring in breast cancer patients treated in the neoadjuvant GeparQuattro trial. Clin. Cancer Res. 16, 2634-2645.

Stoecklein, N. H., Niederacher, D., Topp, S. A., Fohrding, L. Z., Vay, C., Knoefel, W. T., Kasprowicz, N. S., Hepp, P. G., Mohrmann, S., Janni, W., Stratmann, A., Krahn, T., Honisch, E., Raba, K., and Fischer, J. C. (2012). Effect of leukapheresis on efficient CTC enrichment for comprehensive molecular characterization and clinical diagnostics. J. Clin. Oncol. 30(Suppl.), abstr. e21020.

Stott, S. L., Hsu, C. H., Tsukrov, D. I., Yu, M., Miyamoto, D. T., Waltman, B. A., Rothenberg, S. M., Shah, A. M., Smas, M. E., Korir, G. K., Floyd, F. P. Jr., Gilman, A. J., Lord, J. B., Winokur, D., Springer, S., Irimia, D., Nagrath, S., Sequist, L. V., Lee, R. J., Isselbacher, K. J., Maheswaran, S., Haber, D. A., and Toner, M. (2010a). Isolation of circulating tumor cells using a microvortex-generating herringbone-chip. Proc. Natl. Acad. Sci. U.S.A. 107, 18392-18397.

Stott, S. L., Lee, R. J., Nagrath, S., Yu, M., Miyamoto, D. T., Ulkus, L., Inserra,
E. J., Ulman, M., Springer, S., Nakamura, Z., Moore, A. L., Tsukrov, D. I., Kempner, M. E., Dahl, D. M., Wu, C. L., Iafrate, A. J., Smith, M. R., Tompkins, R. G., Sequist, L. V., Toner, M. Haber, D. A., and Maheswaran, S. (2010b). Isolation and characterization of circulating tumor cells from patients with localized and metastatic prostate cancer. Sci. Transl. Med. 2, $25 \mathrm{ra} 23$.

Stratmann, A., Fischer, J. C., Niederacher, D., Raba, K., Schmitz, A., Kim, P. S., Singh, S., Stoecklein, N. H., and Krahn, T. (2012). A comprehensive comparision of circulating tumor cell capturing technologies by apheresis of cancer patients. J. Clin. Oncol. 30(Suppl.), abstr. e21017.

Talasaz, A. H., Powell, A. A., Huber, D. E., Berbee, J. G., Roh, K. H., Yu, W., Xiao, W., Davis, M. M., Pease, R. F., Mindrinos, M. N., Jeffrey, S. S., and Davis, R. W. (2009). Isolating highly enriched populations of circulating epithelial cells and other rare cells from blood using a magnetic sweeper device. Proc. Natl. Acad. Sci. U.S.A. 106, 3970-3975.

Tan, S. J., Yobas, L., Lee, G. Y., Ong, C. N., and Lim, C. T. (2009). Microdevice for the isolation and enumeration of cancer cells from blood. Biomed. Microdevices 11, 883-892.

Tinhofer, I., Hristozova, T., Stromberger, C., Keilhoiz, U., and Budach, V. (2012). Monitoring of circulating tumor cells and their expression of EGFR/phospho-EGFR during combined radiotherapy regimens in locally advanced squamous cell carcinoma of the head and neck. Int. J. Radiat. Oncol. Biol. Phys. [Epub ahead of print].

Vona, G., Sabile, A., Louha, M., Sitruk, V., Romana, S., Schutze, K., Capron, F., Franco, D., Pazzagli, M., Vekemans, M., Lacour, B., Brechot, C., and Paterlini-Brechot, P. (2000). Isolation by size of epithelial tumor cells - a new method for the immunomorphological and molecular characterization of circulating tumor cells. Am. J. Pathol. 156, 57-63.

Went, P. T., Lugli, A., Meier, S., Bundi, M., Mirlacher, M., Sauter, G., and Dirnhofer, S. (2004). Frequent EpCam protein expression in human carcinomas. Hum. Pathol.35, 122-128.

Wesley, J., Whitmore, J., Trager, J., and Sheikh, N. (2012). An overview of sipuleucel-T: autologous cellular immunotherapy for prostate cancer. Hum. Vaccin. Immunother. 8, 520-527.

Wittekind, C., and Neid, M. (2005). Cancer invasion and metastasis. Oncology 69(Suppl. 1), 14-16

Wulfing, P., Borchard, J., Buerger, H., Heidl, S., Zanker, K. S., Kiesel, L., and Brandt, B. (2006). HER2-positive circulating tumor cells indicate poor clinical outcome in stage I to III breast cancer patients. Clin. Cancer Res. 12, 1715-1720.

Zhang, Z., Han, L., Cao, L., Liang, X., Liu, Y., Liu, H., Du, J., Qu, Z., Zhu, C., Liu, S., Li, H., and Sun, W. (2008). Aggregation formation mediated anoikis resistance of BEL7402 hepatoma cells. Folia Histochem. Cytobiol. 46, 331-336.

Zharov, V. P., Galanzha, E. I., Shashkov, E. V., Kim, J. W., Khlebtsov, N. G., and Tuchin, V. V. (2007). Photoacoustic flow cytometry: principle and application for realtime detection of circulating single nanoparticles, pathogens, and contrast dyes in vivo. J. Biomed. Opt. 12, 051503.

Zheng, S., Lin, H., Liu, J. Q., Balic, M., Datar, R., Cote, R. J., and Tai, Y. C. (2007). Membrane microfilter device for selective capture, electrolysis and genomic analysis of human circulating tumor cells. $J$. Chromatogr. A 1162, 154-161.

Conflict of Interest Statement: The authors declare that the research was conducted in the absence of any commercial or financial relationships that could be construed as a potential conflict of interest.

Received: 01 June 2012; accepted: 13 June 2012; published online: 02 July 2012.

Citation: Greene BT, Hughes $A D$ and King MR (2012) Circulating tumor cells: the substrate of personalized medicine? Front. Oncol. 2:69. doi: 10.3389/fonc.2012.00069

This article was submitted to Frontiers in Cancer Molecular Targets and Therapeutics, a specialty of Frontiers in Oncology. Copyright (๑) 2012 Greene, Hughes and King. This is an open-access article distributed under the terms of the Creative Commons Attribution Non Commercial License, which permits noncommercial use, distribution, and reproduction in other forums, provided the original authors and source are credited. 